\title{
ENGAGEMENT OF THE ARMED FORCES IN SUPPORT OF CIVILIAN AUTORITIES IN CRISIS SITUATION AND STATE OF EMERGENCY
}

\author{
Zoran Nacev ${ }^{49}$ \\ Ss. Cyril and Methodius University, Faculty of Philosophy, Institute for Security, \\ Defense and Peace \\ Igor Gjoreski ${ }^{50}$ \\ Ministry of Defense of the Republic of North Macedonia
}

\begin{abstract}
For the need ofengagement of theArmed Forces in support of civilian authorities and citizens is a topic on which there is a comprehensive consensus both at the national level and within the NATO member states. Controversy over the mechanisms of engagement, the precise definition of tasks, and the duration of the engagement of the Armed Forces.The Army of the Republic of North Macedonia supports the civilian component of the defense system in conditions when the other state institutions (including local self-government) will not be able to cope with the crisis, when there are threats to critical infrastructure and when the security and borders of the country are endangered. Whenever support is sought from the Army, it should be borne in mind that Armed Forces units should not be the first responder. The Armed Forces has to be engaged only in a situation where the crisis or state of emergency exceeds the capacities and capabilities of other state institutions and local authorities. The situation caused by the COVID 19 outbreak put to the test the civil readiness and resilience of the society in dealing with such situations and brought to the surface the necessity of engaging the capacities and capabilities of the Armed Forces in different circumstances. Also, there was a need for normative and legal regulation of engagement of the Armed Forces units in support of civilian authorities and citizens in peacetime, in natural disasters, in crisis and state of emergency, as well as to prevent its possible abuse. The need for building resilience and response mechanisms in case of natural disasters and emergencies are an active component both at the national level of each country and in the context of integral and solidarity engagement of the Alliance. NATO's approach to building resilience is based on the concepts of the Whole of Government Approach and the Whole of Society Approach.
\end{abstract}

Key words:Use of the Armed Forces, Crisis Situation, State of Emergency, COVID 19.

\section{Introduction}

One of the Defence missions of the Armed Forces (AF) determined according to the Strategic Defence Review 2018 (SDR2018) is supporting civilian authorities and citizens. More specifically, "this mission concerns support for Ministry of the Interior (MOI) forces in dealing

\footnotetext{
${ }^{49}$ Contact address: nacevz@fzf.ukim.edu.mk

${ }^{50}$ Contact address: igor.gjoreski@mod.gov.mk
} 
with security threats and risks, as well as support for other national and local authorities and citizens, when dealing with crises such as natural disasters, technical-technological disasters, large-scale epidemics, the consequences of climate change and other circumstances that disrupt internal stability (SDR, 2018, p.16).Thereby, in the 2020 Defense Strategy of the Republic of North Macedonia (Defence Strategy 2020) in paragraph 52, this mission is supplemented and it is clarified that "in situations where the responsible state institutions (including local government) lack the capacity to cope with crises, including internal security threats, threats to critical infrastructure, natural disasters, technological incidents, epidemics and climate, threats to the borders of the Republic of North Macedonia, the AF will support the civilian component of the defence system, as well as the police, in accordance with the established procedures" (Defence Strategy, 2020,p.15). Usually, the AF is engaged to support the civilian authorities in peacetime, in case of natural disasters, in crisis and in a state of emergency. The order to engage the AF is the under authority of President which is the Supreme Commander of the AF (Constitution of the Republic of Macedonia, 1991) in accordance with the constitutional and legal competencies.

In the past years, in several situations, the engagement of some units of the AF in supporting of civilian authorities was requested mainly by the local authorities in dealing consequences caused by natural disasters, then in support of the Protection and Rescue Directorate (PRD) in extinguishing the forest fires, and by the $\mathrm{MOI}$ in dealing with migrants on the southern and northern borders, as well as by the Ministry of Health $(\mathrm{MoH})$ in dealing with the pandemic caused by COVID 19.

However, when seeking support from the AF it should be borne in mind that the use and engagement of AF units in support of civilian authorities should not be the first option. It should be only in a situation where lack the capacity to cope with crises of the institutions involved and local government are exhausted, and the crisis or state of emergency exceeds the capacities and capabilities of other state institutions and local authorities. Thereby, for proper and efficient realization of the activities, joint planning, coordination, training is needed to deal with the challenges and consequences of the crisis or state of emergency among all involved entities.

\section{Engagement of the NATO Armed Forces in Supporting of Civilian Authorities in Alliances Member Countries}

The need to build mechanisms for building resilience and response in case of natural disasters, crisis situation and state of emergency is an important content of the activities of the member states, but also is in the context of integral and solidarity engagement of the Alliance. It is in the function of building resilience for the successful implementation of the three core tasks of the Alliance - collective defense, crisis management and cooperative security. As it is known, the collective defense implies the use of the AF in exercising the right to individual, ie collective defense of the state if it is attacked. From other hand, crisis management operations are closely related with engagement and conducting crisis management operations in which the AF are placed in support of the civilian authorities in crisis situation, ie state of emergency. The use of AF in the context of cooperative security implies engagement in international operations led by the Alliance and contributing to global peace, but also host nation support of the country in dealing with the challenges and consequences of natural disasters and man- 
made catastrophes. Within the Alliance, the decision to use the AF is a national responsibility and therefore all their activities and engagements inside and outside the country should be coherently planned and coordinated.

The past experiences of NATO countries is that each member state in dealing with such situations to develop its own Comprehensive Plan for engagement of government institutions and agencies in civil emergencies Whole of Government Approach (WGA), ie Comprehensive Plan for engagement of the whole society (Whole of Society Approach (WSA) in dealing with such situations (Brussel Summit Declaration, 2018). It is recommended that the AR not be the "first responder" but primarily to contribute to dealing with the consequences in accordance with the functionalities of all involved institutions and their capabilities and capacities in the given situation. In this case, the AF need to be understood as a proactive segment of the WGA concept and defense system, not just as a subject. Also, in accordance with the Seven Baseline Requirements (SBR), the Alliance has prepared procedures and institutional mechanisms for acting in civil emergencies within the Euro - Atlantic Disaster Respond Coordination Center - EADRCC.The EADRCC is NATO's principal civil emergency response mechanism in the EuroAtlantic area. The Centre functions as a clearing-house system for coordinating both requests and offers of assistance mainly in case of natural and man-made disasters, pandemic, climate changes and other non military threats (EADRCC, 2020).

The second segment linking the crisis situation and state of emergency and eventual state of war in the Alliance is the challenge of building resilience through the SBR and Host Nation Support (HNS). Although this is primarily a competence of civilian preparedness, it should be understood as a complementary part of civil-military relations that are of particular importance for dealing with potential civil emergencies. In the future, they need to be developed and within them to harmonize all specific activities, measures, procedures and competencies that would precisely determine the scope of engagement, place of contribution and the role of the AF in dealing with the relevant civil emergency or state of war (Kuzmanovski, 2021).

What should be a continuous challenge is that the basis for building the resistance of the state should not stop only with the implementation of the SBR, but must be extended to all areas of social life, especially in the communication and digital field, ie in cyber domain and hybrid threats. Building resilience should include capabilities and capacities building to deal with cyber-attacks while providing secure communication, as well as resistance to hybrid threats and disinformation (Kuzmanovski, 2021). It is necessary to ensure the security/resilience of networks and information systems and critical services in support of protection of overall critical infrastructure. However, this is complicated by the absence of legal regulations that would regulate the determination, organization and protection of critical infrastructure in a planned and systematic manner.

The support of civil institutions in various civil emergencies situations is invaluable for a society because it instills in citizens a sense of security and confidence in the functioning of society. Therefore, it is necessary to prepare comprehensive plans for the functioning of the state in civil emergency situation. This would provide mechanisms and procedures for effectively dealing with the consequences of natural disasters, man-made catastrophes, epidemics, climate change and other non-military threats. Comprehensive planning provides the necessary capacity for prevention and an appropriate national response to support 
civilian institutions in civil emergencies and crises. Ensuring comprehensiveness of the state defense capabilities development requires "coordinated inter-ministerial cooperation with relevant governmental and non-governmental institutions and enabling forces and expertise to respond to modern challenges" (Defence Strategy, 2020,p.11).

The WGA \& WSA provide a precise and clear definition of the role that each state institution, agency and part of the non-governmental organizations and other entities would play in crisis situation and state of emergency. This implies an obligation not only to develop, but also to maintain the capacity and capabilities to deal with the consequences of natural disasters or man-made catastrophes, pandemics, climate change and the like. That is, the bodies of the state administration preventively, but also every institution and agency, as well as other international organizations, non-governmental organizations and other entities should have developed their own detailed plan for work and functioning in crisis situation and state of emergency. Thereby, all plans of the state institutions and the non-governmental sector should be united in a comprehensive plan of action in crisis situation and state of emergency. In principle, the "guardian" of such a plan should be the institution responsible for crisis management or, ultimately, the Government. This, basically, is not something new for us, because this conceptual approach to action and organization in case of crisis situation and state of emergency was a functional and integral part of the defense system of the Republic of Macedonia until the mid-nineties of last century.

\section{Reasons for the Armed Forces not to be the "first responder" in crisis situation or state of emergency}

There are several reasons why the AF should not be the "first responder" in a crisis situation or state of emergency. They are primarily related to the realization of the constitutional function of the AF for protection and defense of the territorial integrity and independence of the state and the realization of collective defense which as an obligation arises from NATO membership. Namely, if the use of the Army in peacetime situation within the state is planned, then it should be precisely determined and regulated. That is, under what conditions, with what capacities, in what way and in which situations it can be used. Otherwise, every move of the AF can be interpreted as an abuse of AF capacity. If you look at our regulations, you can see that the use of the AF in peacetime is regulated by the Defense Law, the Army Service Law, Crisis Management Law, and Low of Protection and Rescue. On the other hand, the procedures, missions and tasks of use and engagement are regulated by bylaws.

After all, the primary function of the AF is defense, ie its engagement and use is associated with defense in war or in a state of war. As it is known, the AF concentrates the greatest physical strength and fighting power of the state, which is exclusively engaged and used in case of threat to the territorial integrity and independence of the country from an external organized force. To achieve this goal, among other things, it means the use and maintenance of an appropriate level of readiness of operational military and other equipment that is expensive and cannot be purchased on the free market "overnight". Namely, its procurement is subject to special agreements at the level of governments and by order. Hence, any reckless and irrational use of military equipment reduces the readiness of the AF, increases the cost of maintaining it, and may jeopardize its ability and readiness to respond in the event of a military threat. 
Hence, it is necessary to determine precisely the time frame, in which circumstances, which units and which equipment will be engaged, but also who will bear the costs for the use of the AF in crisis situation or state of emergency. There is no doubt that the AF exists for the society and is in the service of the people, but it should not be forgotten that the cost of engaging a soldier or military equipment is quite high, hence its use should be rational.

Past experience has shown that the use of part of the AF in support of civilian authorities has implications for the defense budget that is spent on the performance of the functions of other government institutions, without adequate compensation. In fact, if the non-systemic costs are primarily borne by the already modest defense budget, the realization of the basic constitutional function of the AF may be called into question and its readiness may be disrupted. It seems to us that the question related to the financial implications ${ }^{51 *}$ of use of the AF in support of civilian authorities should be raised and who will compensate for that. Hence, what can and should be taken into account buy budget users, in phase of annual state budget creating and distributing by institutions is to provide funds for refunds or reimbursement in case of requesting the engagement of part of the AF in support of civil institutions in a clearly specified procedure for determining real costs. ${ }^{52 * *}$

Seen in a broader context, the AF comes from the people and must always be at the service of the people and the citizens, and that includes the engagement of part of the AF in support of the citizens and the civilian authorities. At least so far, the AF is always here to help the citizens and if necessary will engage all available resources and capacities to deal with and respond to certain crisis situations. It should not be forgotten, however, that a prominent British politician and thinker said that ten years of inadequate funding and irrational use of the AF's capabilities and capabilities led to its utter exhaustion and incompetence, which in itself posed a security challenge to the state. In other words, the resources of the AF should be spent extremely carefully, and great care must be taken when requesting the use of the AF in support of civilian authorities and citizens, ie state institutions and local self-governments.

\section{Engagement of Armed Forces in Crisis Situation}

The engagement of part of the AF in a crisis situation is regulated by the Crisis Management Law of $2005-C M L$, with bylaws and internal procedures arising from legal solutions. According to Article 30 of the CML, "a crisis situation is declared in order to deal with a crisis that poses a risk to the well-being, health and lives of people and animals or a danger to the security of the Republic or part of it. The Government, in accordance with its competence, makes a decision on the use of the resources of the state administration bodies, the local selfgovernment and the City of Skopje, as well as on their management in case of crisis. When a crisis situation is declared, the crisis management in accordance with the Law is functionally under the competence of the Crisis Management Center."

51 *Within this issue, the costs borne by the Ministry of Defense should be taken into account, which refer to the training of pilots for the needs of the Ministry of Interior in the Pilot Training Center, 4-year education at the Military Academy. for the needs of the Crisis Management Center - CMC and PRD, as well as the use of funds to support other government institutions and agencies that have a primary role in crisis management.

$52{ }^{*}$ This would basically refer to those institutions and entities that have so far need to engage the AF in certain circumstances. 
The Government declares a crisis situation and it is in its competence to determine the territory to which the crisis situation refers. Article 35 of the CML (2005) clarifies that "part of the AF in support of the police is engaged when the crisis threatens the security of the state, and the state administration bodies do not have adequate resources and means to prevent and deal with it." Using this legal right, the Government on August 19, 2015 adopted a "Decision on the existence of a crisis situation due to the increased flow of entry and transit of migrants through the territory of the Republic of Macedonia" (Decision No. 110/1, 2015). Based on the provisions of the mentioned article, at the proposal of the Government, the President of the Republic endorsed a Decision ordering the engagement of part of the AF units in support of the border police in securing part of the southern and northern border during the migrant crisis. Military capabilities in support of the Police have been deployed according to the CML.

Tasks assigned to AF in support of border police on part of the southern border included patrolling, closing the crossing routes, engineering support, exchange intelligence, search and rescue, and in theater Airlift. The engagement of some AF units contributed to increasing the security and tranquility of the local population and provided a more comprehensive approach to the treatment of persons who have expressed intention to seek asylum in the Republic of Macedonia in accordance with the recommendations of conventions to which our country was signed. However, the situation on the ground showed that the reasons that led to the crisis situation in part of the territory of the country can not be removed within the legally determined period. Therefore, the option offered by the law was passed, ie to extend the duration of the crisis situation. Namely, according to Article 31 of the CML, the duration of the crisis situation is limited to 30 days. If the crisis continues for more than 30 days, then the Government has two options at its disposal or to ask the Parliament to extend the duration of the crisis, for which it is not specified how long and how many times that extension can be, or to ask to declare a state of emergency, ie a state of war depending on the intensity and challenges of the crisis.

If we carefully look at the data provided by the Mol regarding prevented attempts to cross the state south border illegally, we can conclude that this decision of the Government to extend the duration of the crisis is partially correct.

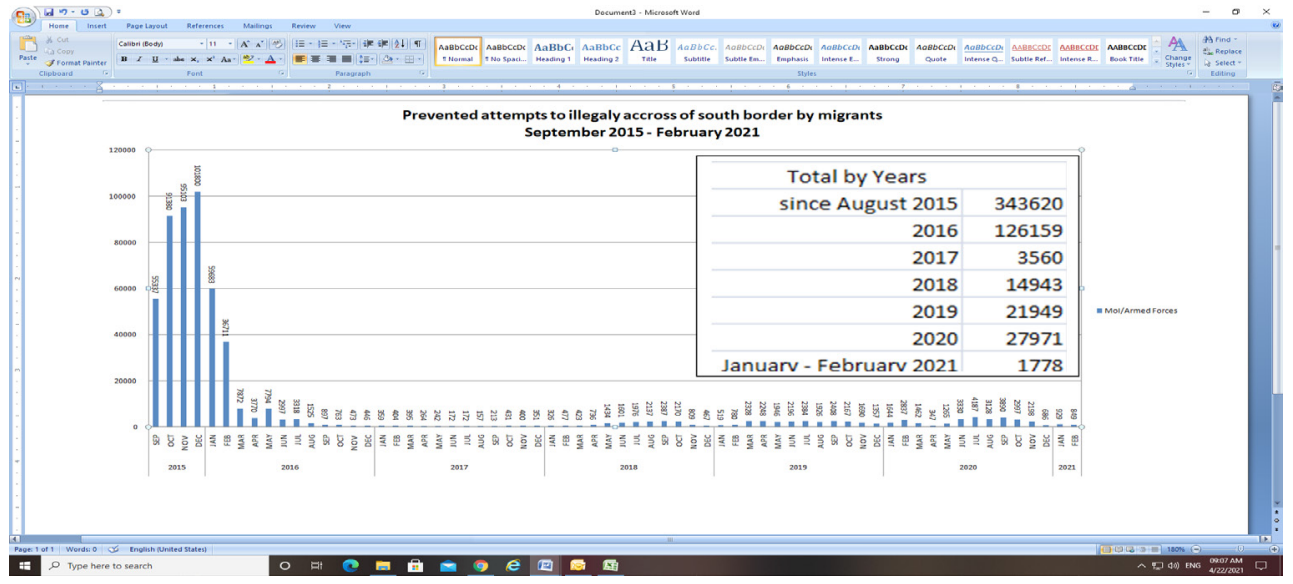

Source: (Ministry of Interior of the Republic of North Macedonia, 2021) 
Namely, from the provided data it can be seen that the peak of the crisis is in the period from September 2015 to February 2016 when the number of illegal attempts to cross the south state border on a daily basis is extremely high. It ranges from 1,850 attempts daily in September to 3,300 attempts daily in December 2015. This number of attempts for illegal crossing of migrants at the beginning of 2016 is still extremely high, but gradually in the next months it began to decline. In September 2016 there were only 897 or 30 attempts for illegal crossing on a daily basis were registered. With some turbulence in the period 20172021, the number of illegal attempts to cross the southern border ranges from an average of 10 attempts in 2017 up to 77 attempts on a daily basis in 2020. This development, ie the drastic reduction of the attempts by the migrants for illegal crossing of the southern border, imposed the dilemma of the justification of further engagement of the $A F$ in support of the police. In the period September 2015 - December 2020, when the AF was engaged in support of the police on the southern border, the Ministry of Defense spent over 3 million Euros for this purpose.

\section{FINANCE RESOURCES SPENT FOR AF ENGAGEMENT IN SUPPORT OF POLICE DURING} THE MIGRANT CRISESS IN EUROS

\begin{tabular}{|c|c|}
\hline 2015 & 152.502 \\
\hline 2016 & $1,366.293$ \\
\hline 2017 & 451.447 \\
\hline 2018 & 320.079 \\
\hline 2019 & 341.394 \\
\hline 2020 & 331.118 \\
\hline Total: & $2,962.834$ \\
\hline
\end{tabular}

(Source: Ministry of Defence of the Republic of North Macedonia, 2021a)

From the graphic and table presentation it can be seen that after August 2016, the trend of attempts for illegal crossings at the state border by migrants has drastically decreased, which raised the dilemma of further engagement of some AF units in support of the police. As we have already pointed out, the use of part of the AF was decided by the President of the Republic, who has the right at any time to reconsider the decision to use part of the AF in dealing with the crisis situation. In this case, and having in mind the positive development of events and the drastic reduction of attempts at illegal crossings, the President does not use his legal opportunity to reconsider the need and justification for further engagement of AF units in support of the border police on the southern border. The crisis situation on part of the southern border has been continuing for more than 5 years, raising the question of the justification of the crisis situation and whether the long-term security threat to part of the southern border could be resolved with certain measures as it was done with the declaration of a state of emergency caused by uncontrolled spread COVID 19 in March 2020.

However, considering the scale of the threat and the inability to prevent it within 30 days, the Government used the right given to it by Art. 30 of the CML and proposed to the Parliament to declare a state of emergency. In the case of the crisis situation on part of the southern border, the Government did not use that right and did not propose to the Parliament such an option, but, on the contrary, it is proposed to the Parliament continuously every 6 (six) months to make Decisions to extend the crisis situation of the southern border (Decision 
no. 08- 4441/1, 2015), and the engagement of the AF is automatically extended. The crisis situation on the southern border officially ended on April 1, 2021. The Parliament did not make a new decision to extend it. Thus, the engagement of AF on the southern border in support of the police became pointless. The Supreme Commander issued an order and withdraws the AFfrom the southern border.

Hence, it can be concluded that so far the procedures for the use of part of the AF units in support of the civilian authorities (in support of the forces of the Mol) and the citizens have been partially regulated. More specifically, the use of part of the AF in support of the police is regulated by a Rulebook adopted by the President of the Republic. The Rulebook clearly states the type, number of forces and capacities of the AF units, purpose and tasks for which they are required and duration of the activity and engagement. The readiness, training and exercises for possible engagement of part of the AF in support of the police are regulated in more detail by the Guidelines for operational and other procedures of the AF in support of the police in case of crisis situation adopted by the Minister of Defense with the prior consent of the Minister of Interior (Crisis Management Law, 2005). However, the Law does not stipulate what capacities and capabilities will be engaged by the AF in case of dealing with consequences caused by natural disasters or man-made catastrophes. Therefore, in the future it is necessary to work on further regulation of the bylaws and procedures that treat the use of AF units in support of other state institutions in crisis situation or in state of emergency.

\section{Engagement of the Armed Forces in State of Emergency}

Regarding the normative legal order for engaging the AF in a state of emergency, it can be concluded that no legal regulation provides for and regulates the engagement of $A F$ units in support of civilian authorities and citizens in a state of emergency. Only the state of emergency is treated by the Constitution (1991) in Article 125 which states that "A state of emergency occurs when major natural disasters or epidemics occur. The existence of a state of emergency on the territory of the Republic of Macedonia or its part is determined by the Parliament on the proposal by the President of the Republic, the Government or at least $30 \mathrm{MPs}$. The decision determining the existence of a state of emergency is made by a two-thirds majority vote of the total number of MPs and is valid for a maximum of 30 days. If the Parliament cannot convene, the decision for the existence of a state of emergency is made by the President of the Republic and submitted to the Parliament for confirmation as soon as it is able to convene "(Constitution, 1991,articles.125-126). However, if something is not prescribed as in the case of the engagement of the AF in a state of emergency, it does not mean that its engagement is prohibited, but that it is not properly regulated. The state of emergency should be seen as an extension of the crisis to a more pronounced scale with greater restrictions on regular functionality. This is in a way hinted at by Article 31 of the CML (2005) which provides for a transition from crisis situation to state of emergency.

Following the declaration of a state of emergency as a result of the pandemic caused by COVID 19, a debate on normative legal regulation of the state of emergency was stimulated. The challenge is whether we really need a legal solution for a state of emergency or we need to precisely determine the capacities that would be additionally engaged in relation to those entities, mechanisms and resources that were previously engaged in dealing with a crisis 
situation. If the idea of legally regulating the state of emergency is accepted as opposed to the idea of accurately determining the capacities that would be engaged in relation to those that were previously engaged before the declaration of the state of emergency, then it raises the dilemma whether "if from epidemic we transit to pandemic, does the measures taken to deal with epidemic or the existing measures to deal with epidemic can apply in case of a pandemic or not." Whichever approach is taken, a clear distinction must be made between what is meant by a crisis situation and what is meant by a state of emergency. That is, it is necessary to clearly and unequivocally specify when and under what conditions one goes from a crisis situation to state of emergency and ultimately to a state of war. By the logic of things, the crisis situation, the state of emergency and the state of war should be a "holy trinity" for the engagement of the AF under certain conditions and with clearly defined procedures. Basically, the state of emergency is a wider type of crisis situation in the country in which the Government has greater powers to act quickly and make decisions in order to more effectively deal with the consequences and challenges arising from such a situation (Kuzmanovski, 2021). The key difference between declaring a state of emergency or crisis situation is in the scope and structure of the measures that can be taken for prevention and protection, the territory in which such a state is declared, the scope, and the possibilities for remediation of the consequences caused by the state of emergency. When declaring a state of emergency, the responsibilities and competencies of the Government increase, especially in the part of passing Decrees with Force of Low.

\section{Lessons Learned from Armed Forces Units Engagement in State of Emergency Caused by COVID 19}

As a result of the measures to prevent outbreak of Coronavirus - COVID 19, on March 13, 2020, the Government determined the existence of a crisis situation in part of the territory of the Republic of North Macedonia, in the municipalities of Debar and Centar Zupa (Government Decision No. 44-2240 / 1, 2020). With the determination and declaration of the crisis situation, the Steering Committee from the Crisis Management Center was automatically activated with competencies to manage the crisis situation. However, the crisis situation, although declared 30 days, lasted only 5 days. The reason for that was the uncontrolled spread of COVID 19 worldwide, but also within the borders of North Macedonia. Therefore, the Government on March 18, 2020, based on Article 125 paragraph 1 of the Constitution of the Republic of North Macedonia submitted a Proposal to the Parliament to determine the existence of a state of emergency on the territory of the Republic in line to prevent outbreak and to deal with COVID-19, according to a pandemic declared by the World Health Organization. In situation of dissolved Parliament due to early parliamentary elections and his inability to meet and decide, the President of the Republic in accordance with his constitutional competencies, endorsed a "Decision to establish a state of emergency throughout the country" (Decision No. 08-526 / 2, 2020). In the period from March 18 until June 13, 2020, the state of emergency declared due to COVID - 19, four times was extended with Decisions by the President of the Republic.

Three days after the crisis situation was declared, and two days before the declaration of the state of emergency, on March 16 the Minister of Defense announced that the AF are ready to support the forces of the $\mathrm{Mol}$ in the municipalities where a crisis situation was declared. However, when the state of emergency was declared (March 2020), the support of the AF was 
extended not only to the forces of the Mol, but also to the Ministry of Health and the health care system. The Government decided to "Involve the Army directly in support of all state institutions in dealing with the consequences of the Coronavirus and to be on the front line to protect the health of citizens wherever necessary" (Sekerinska-Jankovska, 2020). For that purpose, on March 20, 2020, as an ad hoc solution in the absence of a Law, the Government adopted "Decree with legal force for determining the tasks of the AF of the Republic of North Macedonia for the duration of the state of emergency" (Decree No. 44-2409 / 1, 2020).

With the Decree, officially gave the legitimacy of the use and engagement of AF to support the civilian authorities in situation of declared state of emergency. Also, the tasks of the AF in support of the police forces of Mol and tasks to support other civil authorities in order to prevent COVID 19 outbreak, were defined by this Decree. In order to ensure easier coordination among the AF and other state institutions, an Operational Center has been established.

Regarding the Decision to engage the AF in support of the civilian authorities, the Minister of Defense will emphasize that they "... were not easy, but they were justified. They are justified because the whole world, and not only us, is facing an epidemic, a danger that no one could have imagined. An epidemic and a danger that requires us all to be mobilized and focused, and that is why the AF has rightly made available everything it has and everything it can to help the police, the state bodies, but also the whole country "(Sekerinska-Jankovska, 2020a).

During the state of emergency caused by the pandemic, the AF personnel actively contributed not only to the protection of the health of the citizens but also to reducing the consequences of this threat to the security of the state. The focus is basically on three sets of tasks that will be performed by AF personnel during the state of emergency.

According to the Decree, the AF were engaged throughout the country, primarily in support of police forces in border security and surveillance, and temporarily took full control and surveillance of the state border, in order to prevent the entry and exit of all persons who intend to make an illegal crossing of the state border. In that way, part of the police capacities were relieved of their duties at the border and they were redirected to perform security tasks as well as control over the implementation of the Government measures to prevent outbreak of the pandemic.

The second task was related to authorizing the AF personnel to support the police forces to conduct inspections, ie control of entry and exit of roads to settlements by establishing mobile checkpoints and checkpoints in the areas of engagement, especially in crisis areas. By other decrees, such authorizations of AF personnel were extended to the part of joint policearmy teams so that they can exercise control over the observance of curfew, control of selfisolation and if self-isolation is not respected, immediate measures should be imposed, but also these persons to be sent to state quarantine and state isolation (Sekerinska-Jankovska, 2020a). AF personnel were also active in supporting local government and other state institutions in their overall efforts to prevent the pandemic and its aftermath.

The third task given to the AF was related to the physical security of vital facilities that were previously provided by the Mol. This means that the AF has temporarily taken over the security of facilities such as the Parliament, the Government, Prisons and facilities for state 
quarantine and other facilities of critical importance to the state. In this situation, the AF did not function independently in carrying out additional tasks but they worked together in combined teams with the police.

In May 2020, the MoD and AF activated and deployed two military capacities to support health care system of the country. The first key capacity was the Role 2 Basic Land Medical Treatment Facility as support not only for the AF, but above all as support for public health, thus greatly increased the capacity of the Clinic for Infectious Diseases and Febrile Conditions. The second key capacity that was made available during the pandemic is helicopter transport, which if the need arises can be activated in an extremely short period of time (SekerinskaJankovska, 2020b).

On 5 November 2020, the president of the Republic and Supreme Commander of the AF, used legal rights according to Defence Law Article 18, paragraph 1, point 5, and Article 25, and sign an Order of AF engagement of part of AF units in peace time or in situation when crisis situation or state of emergency or state of war is not proclaimed. According to the Order, some of the AF units and military resources were engaged as non-military forces to carry out tasks to support government institutions in dealing with the outbreak of the COVID 19 pandemic.The General Staff engaged military medical capabilities, and medical means to support the health care system and Ministry of Health, and also have provided logistic support in transportation of necessary medical means and equipment. Also, "The AF helped to provide warehouse space for storage of protective and medical assets and equipment, setting up tents and other accommodation facilities intended for the medical treatment of COVID 19 infected people, as well as for disinfection of premises and surfaces" (Pendarovski, 2020). To carry out these tasks, the medical, transportation and CBRN capacities have made available to Ministry of health and health care system.

On 20 November, the Government on the Steering Committee and Security Council proposal made a Decision on the existence of a crisis situation on the entire territory of the country for a period of 30 days. This Decision was in order to effectively deal with the consequences of the pandemic caused by COVID 19. As part of the implementation of the measures resulting from the newly declared crisis, the Government, despite the current order of the President for engagement the part of the AF units in peacetime as a non military in support of civilian authorities, additionally requested, inter alia, the re-engagement of part of the AF units in support of the civilian authorities. As part of this crisis situation, about thirtyAF medical personnel were engaged. They were deployed across health care and medical centers to assist medical staff in hospitals across the country.

According to the data obtained through free access to information from the Ministry of Defense on the engagement of part of the AF units in peacetime, crisis situation and state of emergency in 2020 in support of other state institutions, primarily the forces of the Ministry of Interior and the Ministry of Health the following can be stated.

During the crisis from November 20 to December 10, 2020, a total of 280 members of the $A F$ were engaged on a daily basis in support of the civilian authorities. From these members of the $A F$ in support of the Mol forces on a daily basis were engaged a total of 130 members, of which 50 members on the territory of Skopje, and 80 members outside Skopje. While in support of the Ministry of Health on a daily basis were engaged 45 military medical personnel 
as doctors and other medical staff (Cjurcinovski, 2020). The remaining 105 members of the AF were deployed as needed to support Local Self Government. For the engagement of those military personnel the MoD spent around 40.000 Euros (Ministry of Defence, 2021b).

In total 110 medical military personnel (of which 17 doctors, 47 medical technicians and 46 support personell) was engaged during the crisis situation and state of emergency in the period from 13 March until 13 June 2020. These personnel were engaged in support of the public health care systemin the COVID centers(Министерство за одбрана, 2020 b). While for the engagement of the military medical personnel during the crisis and the state of emergency for the period from March 13 to June 13, 2020, the MoD spent a total of 623.000 Euros (Ministry of Defense 2021b). There are no data for the engagement of the other military personnel in support of Mol forces for this period. In total, for the engagement of the AF in support of the civilian authorities during the 140 days of crisis and state of emergency caused by COVID 19 in 2020, a total of just over 663.000 Euros were spent.

Taking into account that reimbursement of the costs of engaging the AF in support of the civilian authorities were financed by the MoD budget, it also called into question the normal functioning of the AF services and obligations. Additional challenge to this was the reduction for more than 25 million Euros of the defence expenditures in May 2020 by central budget rebalance. Most of these reduced funds were by the equipping category. Firstly planed $18.23 \%$ for procurement of new major equipment were reduced to $11.43 \%$ from 2020 defence spending (Ministry of Defence, 2020a). The reduction of costs postpones some of the already initiated projects for procurement of new major equipment in accordance with the LongTerm Defense Capabilities Development Plan 2019-2028. Any further postpone of the new equipment procurement for the AF needs will seriously jeopardizes the future engagement of some AF units in support of the civilian authorities in crisis situation and state of emergency or in case of natural disasters. This imposes the need to find appropriate mechanisms to cover such unforeseen costs from engagement of the AF from other sources, and not only from the defence budget, i.e., to fine mechanisms for more appropriate sharing the burden. The options are mainly in a wider range and are related to the allocation of funds in the central budget or from the funds of those institutions that most often use the "services" of the $\mathrm{AF}$ and up to the preparation of a price list for the engagement of military personnel on a daily basis. In any case, all these options should be seen flexibly because the AF comes from the citizens and serves to the citizens, because of which the support, saving lives, as well as the protection of property, have no price. However, it should be had in mind that expressing solidarity and engaging the AF must not disrupt its combat readiness. By regulating the appropriate compensation for the engagement of the AF personnel in support of the civilian authorities, the possible future disturbances of the normal functioning of the AF would be prevented.

\section{Conclusion}

The engagement part of the AF units in the state of emergency in support of other state institutions in dealing with COVID 19 imposed the need for legal regulation and clear determination of what the crisis situation is and what the state of emergency is and when we are moving from one to another state. So, there is a need to draft several bylaws that address the engagement of the AF units in support of civilian authorities and citizens in peacetime, 
in case of natural disasters, in crisis situation and in a state of emergency. This includes the preparation of appropriate Standard Operational Procedures for when, where, to what extent and what tasks will be performed by the AF personnel in different situations of engagement in support of civilian authorities and citizens. In doing so, special attention should be paid to the training and exercise in case of possible AF engagement. This is so important in order to avoid past experiences when AF personnel were engaged in performing tasks for which they did not have adequate training and did not have adequate equipment to perform that type of task. It is inappropriate to engage the elite AR units to deal with a consequence of a natural disaster, and at the sometime the local self-government does not do anything in this regard. It is inadmissible to engage AF as a first responder in dealing with consequences of natural disasters, but previously do not engage the protection and rescue forces.

Despite the complexity of the crisis situation, i.e., the state of emergency, at certain moments, from a security point of view, the question is whether the soldiers should be engaged for 24 hours in securing private facilities such as hospitals, banks, and markets and so on. Providing security of such facilities is not the responsibility and obligation of the AF personnel. This is something that can be done by private security agencies that do it in peacetime.

One of the issues that has been asking many times, and there is no appropriate answer, is related to the proper distribution of the burden, i.e., who will bear the costs of the AF engagement in support of the civilian authorities. Will those costs continue to be covered by the defense budget, which on long - term could disrupt the financing of the planned and regular activities of the $A F$, or will the costs be borne by the one at whose request part of the $\mathrm{AF}$ units are engaged or again a hybrid way of co-financing and refund will be found.

The respecting the government's measures to deal with pandemic by the AF was also challenging. Namely, if any of the AF personnel is positive on COVID 19, it means that everyone who was in direct contact with the infected person indoors should be quarantined. This means that entire units of the AF should go into at least two-week quarantine. This in turn could seriously disrupt the AF combat readiness. It is therefore desirable when using part of the AF units in support of the civilian authorities to engage smaller task forces for which they are trained and for which the AF have the appropriate equipment. In that way, the risks to the safety and health of the military personnel, as well as the danger of calling into question the readiness of the $A F$ in fulfilling its constitutional obligations will be minimized.

Insufficiently implemented preparations and the lack of a comprehensive plan for dealing with crisis situation and state of emergency at the state level is probably the most serious issue that requires urgent solving. Namely, the indicated need is more and more expressed in accordance with the Alliance recommendations. It is necessary for every institution and individual entities in the country to prepare their own plans for functioning in situation of natural disasters and in crisis situation and state of emergency. They, should then, be united at the state level under the auspices of the Government into a single Comprehensive plan for the functioning of the state institutions and society in situation when natural disasters have occurred, when a crisis situation, state of emergency or state of war has been declared. It should be specified who coordinates the work in such situations, and what capacities and mechanisms each institution will engage. This means amending and supplementing the existing 
legal regulations, but also adopting new ones that will regulate the identified shortfalls in the functioning of the state and society in a crisis situation or in state of emergency.

In order to be able to fully talk about the implementation of NATO concepts for WGA and WSA, at the national level, as well as for comprehensiveness in achieving the support of the AFto civilian authorities and citizens, it is necessary to integrate the capabilities of the civilian and military dimension of military personnel in AF and civilian defense employees regardless of their legal status.Existing legal solutions and non-unified approach to regulating the rights and obligations of defense personnel have contributed to military personnel being in a much more favorable position (Army Service Law) than civilian defense personnel (Law on Administrative Servants and Law on Civil Servants). Differences in the status of MoD staff are a serious challenge that can further negative affect a consistent response in a crisis situation and in a state of emergency and to undermine the integrity of the defense, as well as to reduce the effectiveness of AF support to civilian authorities.The challenge is that military personnel and civilians in the MoD work on the same or similar tasks and there is a significant difference in terms of privileges, career advancement, promotion and income for the benefit of military personnel.Therefore, in the interest of greater professionalism and equal treatment, it is necessary to take measures to reduce those differences that will contribute to increased efficiency and effectiveness of defense.

Despite all the challenges faced by the conceptual approach to engaging some AF units in support of civilian authorities, cannot be forgotten the element of support in education and training not only of citizens but also of other state institutions that can to be provided especially by higher education institutions in the country. Here a special place and attention should be paid to the active support of the scientific staff of the Institute for Security, Defense and Peace in creating concepts how the AF to support the civilian authorities in different situations, to analyze the lessons learned from past AF engagements, as well as to create mechanisms to enhance cooperation between the AF and civilian authorities and citizens in peacetime. These potentials need to be exploited even in the development and implementation of WGA and WSA in accordance with the requirements and recommendations of the Alliance. This should contribute to raise the level of defense awareness and the role of the AF in society. Among other things, it implies the development of a new concept for getting to know, training and preparing citizens to independently contribute and support state institutions in case of natural disasters, crisis situation and in a state of emergency. In order for all this to be realized, a proactive approach is needed and the involvement of several higher education institutions, primarily in the preparation of curricula, contents and methodological approaches in teaching, training and education not only of state institutions but also of the citizen. It should not be overlooked that the AF despite its engagement throughout the duration of the state of emergency, continuously continued to perform the regular constitutional tasks, as well as the tasks arising from the crisis situation and the state of emergency, as well as to share the burden with other Allies in the field of collective defense, crisis management operations and cooperative security.

\section{References}

Brussel Summit Declaration. 2018. Brussels Summit Declaration issued by the Heads of State and Government participating in the meeting of the North Atlantic Council in Brussels, 11-12 July 
2018. [online] Available at: <https://www.nato.int/cps/en/natohq/official_texts_156624. $\mathrm{htm}>$ [Accessed 5 May 2021].

Constitution of Republic of Macedonia. 1991. Skopje: The Parliament of the Republic of Macedonia 17. November 1991.

Crisis Management Low. 2005. Skopje: The Parliament of the Republic of Macedonia, Official Gazette no.29/05.

Decision no.110/1. 2015. Decision on the existence of a crisis situation due to the increased number of entry and transit of migrants through the territory of the Republic of Macedonia, no.110/1 from 19. August 2015, Official Gazette of RM no. 141/15.

Decision no. 08-4441/1. 2015. Decision approving the extension of the deadline for the existence of a crisis situation due to the increased number of entry and transit of migrants through the territory of the Republic of Macedonia, no.08-4441/1 from 18. September 2015, Official Gazette no. $162 / 2015$.

Decision no.44-2240/1.2021. Decision on the existence of a crisis situation on part of the territory of the Republic of North Macedonia, in order to prevent the outbreak of coronavirus COVID-19 no.44-2240/1 from 13. March 2020, Official Gazette of North Macedonia no.63/20.

Decision no.08-526/2. 2021. Decision on determining the existence of a state of emergency on the entire territory of the country no.08-526/2, 18. March 2020, Official Gazette of North Macedonia no.68./20.

Decree no.44-2409/1. 2021. Decree with legal force for determining the tasks of the AF of the Republic of North Macedonia for the duration of the state of emergency no.44-2409/1, from 21. March 2020, Official Gazette of North Macedonia no.72/20.

Defence Strategy. 2020. Defence Strategy of the Republic of North Macedonia 2020, Skopje: The President of the Republic of North Macedonia. Official Gazette of North Macedonia no.75/20 from 24. March.

EADRCC. 2020. Euro-Atlantic Disaster Response Coordination Centre, [online] Available athttps:// www.nato.int/cps/en/natohq/topics_52057.htm.> [Accessed 4 May 2021].

Gjurchinovski.V. 2020. Interview of the Chief of General Staff for the engagement of the $A F$, the transformation processes and the upcoming activities for the show "And What Now" on MTV 1, 03 [online] Available athttps://www.youtube.com/watch?v=ve778d_yuTo) > [Accessed 4 May 2021].

Ministry of Defence of North Macedonia. 2020a. Defence Expenditures According NATO methodology 2003-2020 гоoguна. Data obtained through free access to public information registered under no. 09-4311/2 from 21. October 2020.

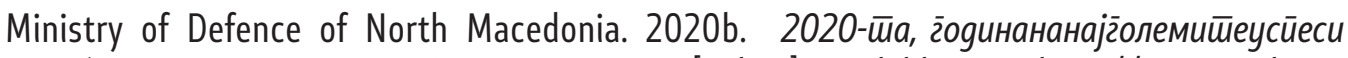

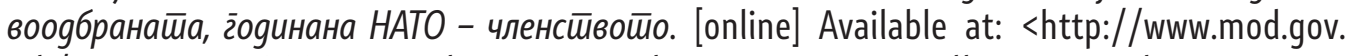
$\mathrm{mk} /$ ?mainnews $=2020$-ta-godina-na-najgolemite-uspesi-vo-odbranata-godina-na-natoclenstvoto\&lang $=m k>[$ Accessed 4 May 2021]. 
Ministry of Defence of North Macedonia. 2021a. Response to a request for public information MoD. No.09-1351/2 from 29.March.2021".

Ministry of Defence of North Macdonia. 2021b. Response to a request for public information MoD No.09-1352/2 from 29.March.2021.

Ministry of Interior of North Macedonia. 2021. Response to a request for public information Mol No.1612-404/1 from 30 March 2021.

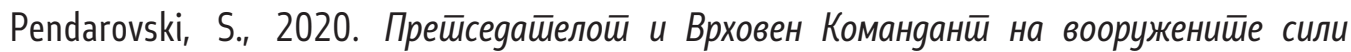
Пендаровски йоййишана среgба за ангазжман на Армијаш̄а. [online] Претседател на Република Северна Македонија. Available at: <https://pretsedatel.mk/\%d0\%bf\%d1\%80\%d0 \%b5\%d1\%82\%d1\%81\%d0\%b5\%d0\%b4\%d0\%b0\%d1\%82\%d0\%b5\%d0\%bb\%d0\%be\%d1\%82\%d0\%b8-\%d0\%b2\%d1\%80\%d1\%85\%d0\%be\%d0\%b2\%d0\%b5\%d0\%bd-\%d0\%ba\%d0\%be\%d0\%bc\%d0\%b0\%d0\%bd\%d0\%b4\%d0\%b0\%d0\%bd\%d1\%82-\%d0\%bd\%d0\%b0-2/> [Accessed 5 May 2021].

SDR. 2018. Strategic Defence Review 2018 of the Republic of Macedonia Towards NATO Membership and "Future Armed Forces 2028 ", Skopje: Ministry of Defence, June, 2018.

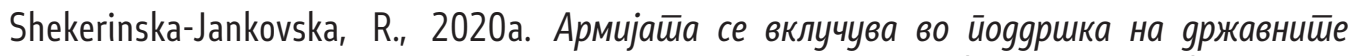

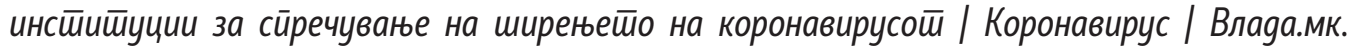
[online] Коронавирус | Влада.мк. Available at: <https://koronavirus.gov.mk/vesti/211463.> [Accessed 5 May 2021].

Shekerinska-Jankovska, R., 2020b. The engagement of the army during the state of emergency caused by the coronavirus pandemic. [online] Mod.gov.mk. Available at: <http://www.mod.gov. $\mathrm{mk} /$ ?mainnews=angazmanot-na-armijata-za-vreme-na-vonrednata-sostojba-predizvikanaod-pandemijata-na-koronavirusot\&lang=en> [Accessed 5 May 2021]. 